\title{
UNIVERSITYOF
}

FORWARD

THINKING

WESTMINSTER用

WestminsterResearch

http://www.westminster.ac.uk/westminsterresearch

Interfunctional coordination: the role of digitalization

Ruiz-Alba, J., Guesalaga, R., Ayestarán, R. and Morales Mediano,

J.

This article is ( ) Emerald and permission has been granted for this version to appear here: http://westminsterresearch.westminster.ac.uk/

Emerald does not grant permission for this article to be further copied/distributed or hosted elsewhere without the express permission from Emerald Group Publishing Limited.

The final, published version in Journal of Business and Industrial Marketing is available at:

https://dx.doi.org/10.1108/JBIM-03-2019-0129

The WestminsterResearch online digital archive at the University of Westminster aims to make the research output of the University available to a wider audience. Copyright and Moral Rights remain with the authors and/or copyright owners.

Whilst further distribution of specific materials from within this archive is forbidden, you may freely distribute the URL of WestminsterResearch: ((http://westminsterresearch.wmin.ac.uk/)).

In case of abuse or copyright appearing without permission e-mail repository@westminster.ac.uk 


\section{Interfunctional coordination: the role of digitalization}

Ruiz-Alba, José L. University of Westminster, Business School. (London, UK).

Guesalaga, Rodrigo. School of Management, Pontificia Universidad Católica de Chile. (Santiago, Chile).

Ayestarán, Raquel. Universidad Francisco de Vitoria. (Madrid, Spain).

Morales Mediano, Javier. Universidad Pontificia Comillas - ICADE. (Madrid, Spain).

[Accepted for publication (5/7/2019) in the Journal of Business and Industrial Marketing.]

\section{Purpose:}

This research investigates interfunctional coordination (IC) in a B-to-B context. More specifically, it explores the role of digitalization as a strategic driver for an effective IC.

\section{Design/methodology/approach:}

Following a qualitative methodology, three studies have been integrated: Study 1 (focus group with five participants); Study 2 (31 in-depth interviews with top executives); Study 3 (online focus group with 9 experts).

\section{Findings:}

One finding is that digitalization is the main driver for IC and can be considered strategic. Other findings show that digitalization can enhance IC, but it was also found that digitalization can have negative side effects on IC.

\section{Originality/value:}

This study contributes to the understanding of the importance of digitalization on IC and also contributes to the conceptualization of IC as a dynamic capability.

Key words: Interfunctional coordination; digitalization; dynamic capabilities.

\section{Introduction}

When business functions work in silos, this hinders the cross-functional coordination and makes it more difficult to create adaptive capabilities, a phenomenon called structural insularity (Day, 2011). Aaker (2009) uses silos as a metaphor to illustrate the fact that some areas with independent functions lack the intention to work with other areas of the firm. If business units work without coordination in different directions, this can generate conflicting goals and make the units, in fact, work as silos. That situation can generate 
visible clashes, but also there is a risk of invisible problems in the form of hidden costs and negative implications for customers. Interdepartmental conflicts may arise from incompatibility of responses and goals (Menon et al., 1997) and these conflicting organizational goals and the lack of cooperation between business areas can create serious dysfunctions (Wall and Lepsinger, 1994). Thus, resource integration is critical and requires processes and forms of collaboration (Kleinaltenkamp et al., 2012). Therefore, interfunctional coordination (IC) becomes crucial for business success.

The notion of IC was defined by Narver and Slatter (1990) as the coordinated utilization of a company's resources in creating superior value for target markets. For these authors, each individual in any business function can contribute to the creation of value for buyers and cooperate to develop a sustainable competitive advantage. It is widely accepted that creating value for customers is not the function of a specific business unit, but of anyone in the organization that has the responsibility to attempt to create customer value (Lafferty and Hult, 2001). In that sense, market-oriented firms have more chances of being successful when developing high levels of IC (Slater and Narver, 1995) and there are several other benefits associated to IC, such as promoting a collaborative culture, creating new knowledge, improving business performance, and enhancing new product performance (Deng and Dart, 1994; Enz and Lambert, 2002; Wooldridge and Minsky, 2002; Kennedy et al., 2003; Rouziès et al., 2005; Altinay, 2010; Lin, Wang and Kung, 2015; Nakata and Im, 2010).

Although there is a general acceptance of the benefits of IC, there are still concerns because the generation of value propositions to customers requires coordinated internal efforts of different business units to achieve common goals (Defee and Stank, 2005). In that sense, some authors found that IC can lead to customer-driven innovative ideas (Altinay, 2010). Working in collaboration can be more beneficial than doing it in silos. This requires developing both internal relationships within the firm and business-tobusiness relationships with customers (Johnston and Bonoma, 1981). However, relationships are not sufficient as skills and capabilities of actors are also needed. In fact, service innovation requires specific knowledge and skills, but also the management of IC (Tajeddini et al., 2017). Therefore, the role of the different actors is something that needs more attention, as this will help to obtain a better understanding of how multiple actors 
in the customer journey interact and contribute to the overall experience (Mora Cortez and Johnston, 2017).

Superior capabilities are required for the foreknowledge of trends before they are completely apparent and adapt effectively (Day, 2011). The concept of dynamic capabilities (Teece et al., 1997) has helped to understand how firms can compete in rapidly changing environments and how IC can be enhanced. Following that rationale, Auh and Menguc (2005) proposed that IC is similar to a dynamic capability and this is something that needs more attention from researchers.

Moreover, the role of IC in B2B marketing has received limited attention by scholars and, in particular, the conditions that influence IC in B2B markets (Mohsen and Eng, 2016), where value is co-created among different actors in a buyer-supplier relationship to achieve higher profits than would be attained by working autonomously (Ramirez, 1999). Previously, De Luca and Atuahene-Gima (2007) studied IC in relation to product innovation performance. Similarly, García-Rodríguez et al. (2007) examined the interfunctional integration between marketing and R\&D from a product development perspective. Years later, Chen et al. (2013) studied IC in B2B relationships from the viewpoint of product innovation and alliance coordination. More recently, Nguyen et al. (2018) studied cross-functional coordination, but with the partial vision of considering departments as competing amongst themselves for limited resources within the firm. Apart from these few exceptions that were focused on specific consequences of IC, to our knowledge, there are no studies that have investigated IC in B2B context from a broader perspective nor have practitioners received specific guidance on the barriers and enablers of IC. Prior research has acknowledged the need for expanding extant knowledge on digitalization of B2B firms (Mora Cortez and Johnston, 2017). Particularly, marketing literature is silent about the role of digitalization in developing IC.

Digital disruption has increased across industries over the past decade. However, digitalization means different things within different functions and at different locations in the business model (Crittenden et al., 2019). According to these authors, digitalization is shifting all business models into a process of digitalization, communications digitalization, and buyer digitalization. Therefore, the role of coordination and collaboration appears to be particularly important. In spite of previous research on IC, the 
eruption of digitalization in firms requiring the provision of rapid solutions in complex and accelerated scenarios has not been yet investigated as a possible driver for IC. Digital transformation is fundamentally not about technology, but about strategy (Rogers, 2016). Several types of knowledge are required to developing strategic B2B marketing capabilities (Mora Cortez \& Johnston, 2018). The more diverse a firm knowledge, the higher the importance of IC. From this perspective, many questions in industrial marketing regarding IC are still unanswered and managers need to understand the main drivers and barriers for IC and, specifically, the role of digitalization.

Consequently, there is a need for expanding the scientific knowledge on IC. In particular, this research advances the literature by addressing three knowledge gaps and allows practitioners to understand: 1) the role of digitalization in IC;2) the barriers and enablers of IC in B2B markets; 3) the development of IC as a dynamic capability.

The aim of this study is to analyze IC in depth while utilizing (resource-based theory) RBT as the theoretical lens. We explore the drivers and the benefits of IC, as well as the barriers. Hence, we intend to discover some of the key internal resources and conditions that need to be integrated with IC to make it a true dynamic capability.

Therefore, this study aims to answer three research questions:

1) What is the current status of IC in B2B in terms of actors, drivers, barriers and enablers?

2) What conditions are needed to consider IC as a dynamic capability?

3) How digitalization contributes to IC?

The paper begins with the revision of the literature on IC. Next, resource-based theory (RBT) and dynamic capabilities are discussed as a theoretical framework for a better understanding of IC. Then, we present the methodology that consists of three studies: study 1 (focus group); study 2 (in-depth interviews) and study 3 (online focus group). The main findings are subsequently discussed in light of the relevant literature. Finally, we present the conclusions, limitations, and the contributions of this research for both academics and practitioners and suggest areas for future research.

\section{Literature review and theoretical approach}




\section{Interfunctional coordination}

Narver and Slater (1990) considered that the concept of market orientation was supported by three main pillars with a behavioral component: a) customer orientation; b) competitor orientation and c) interfunctional coordination. For these authors, market orientation is the culture of the firm that generates more efficiently certain behaviors that create superior value for buyers and, consequently, contributes to increase business performance. Interestingly, in the same year, Kohli and Jaworski (1990) also contributed to the conceptualization of market orientation by focusing on three activities: a) generation of market intelligence; b) intelligence dissemination; c) response to intelligence. For these authors, IC was an antecedent to market orientation.

Market orientation with firms' profitability was also empirically linked (Kohli and Jaworky, 1990; Narver and Slater, 1990). Since the early 90s, market orientation has received full attention from researchers. Similarly, customer orientation and competitors' orientation have been broadly investigated. However, the third component, IC, has not received the attention required given its importance and considering that there is a tendency to adopt a multifunctional approach to marketing as an imperative (Enz and Lambert, 2002).

Some authors understand IC as the harmonization of communication and the sharing of strategic information and other resources along with integration and collaboration of different functional units throughout the firm to create value for customers (Wooldridge and Minsky, 2002; Javalgi et al., 2014). Wooldridge and Minsky (2002) understand IC as a process that integrates customers' and competitors' orientation, providing a coherent action of market response. They also proposed that firms with the highest degree of IC would have the highest performance.

Sharing information becomes an important element of IC, but there are more elements involved in IC, such as formulating and implementing strategies, and developing business plans are key aspects of IC (Deng and Dart, 1994; Altinay, 2010). 
Previous research shows that the coordination of sales and marketing functions can increase the effectiveness of the firm (Rouziès et al., 2005). Similarly, Arnett and Wittmann (2014) demonstrate that IC can facilitate the exchange of tacit knowledge between sales and marketing, thereby enhancing business performance. It is accepted that there is more proximity between sales, marketing and IT (Payne and Frow, 2005); however, authors like Enz and Lambert (2012) claim that the study of interactions should not be limited to representatives from those mentioned areas, but should also include other functions, such as finance, logistics, operations, purchasing, and R\&D (Lambert, 2010).

Joint reward systems, designed from IC perspective, have a positive effect on coordination and integration of marketing with other functional units (Arndt et al., 2011) and the use of financial and non-financial incentives can encourage employees to aim for interfunctional goals and to foster collaboration with other business units (Ladley et al., 2015). In a similar way, it has been shown that cross-functional teams can accelerate speed to market and profit generation (Nakata and Im, 2010; Enz and Lambert, 2012). As resource dependency theory posits, the coordination of different functional units to utilize their knowledge and skills to resolve firm challenges is critical (Pfeffer and Salancik, 1978).

In the context of value co-creation in B2B relationships (Ulaga, 2003), previous research finds that IC facilitates co-creation processes to achieve more profitable buyer-seller relationships (Enz and Lambert, 2002). Moreover, Kennedy et al. (2003) studied how IC can make a positive contribution to the design and implementation of organizational change, whereas Tsai and Hsu (2014) demonstrated how improving the conditions that enhance IC has a positive impact on the role of managers in coordinating different business functions and responding quickly to changes in the market.

\section{Resource-based theory and dynamic capabilities}

Resource-based theory (RBT) considers organizations as bundles of resources and capabilities that allow them to build and execute their strategy (Amit and Schoemaker, 1993; Barney and Arikan, 2001). Helfat and Peteraf (2003, p. 999) define a resource as "an asset or input to production (tangible or intangible) that an organization owns, controls, or has access to on a semi-permanent basis", and a capability as "the ability of an organization to perform a coordinated set of tasks, utilizing organizational resources, 
for the purpose of achieving a particular end result." Capabilities are the glue that bring assets together and enables them to be deployed advantageously (Day, 1994). RBT posits that these resources and capabilities can be considered as a source of competitive advantage to support organizational performance (Wernerfelt, 1984; Barney, 1991) when companies are able to implement value-creating strategies that are unique in relation to those of competing firms, and to adapt resource configurations to changing environments (Eisenhardt and Martin, 2000). Furthermore, RBT argues that, to obtain a sustained competitive advantage, resources and capabilities need to be VRIO: valuable, rare, imperfectly imitable, and supported by the firm's organization (Barney and Hesterly, 2012). First, a resource or capability has to be valuable in contributing to the firm's increase in revenues (effectiveness) and/or reduction in costs (efficiency) while being perceived as valuable by the customer (Barney and Arikan, 2001; Gouthier et al., 2003). Second, a resource or capability is rare if it is highly embedded in the company context and not easily accessible to competitors (Barney and Hesterly, 2012). Third, resources and capabilities may be imperfectly imitable based on unique historical conditions, causal ambiguity, or social complexity (Barney and Clark, 2007). Finally, a firm must have in place the right policies and procedures to exploit completely its resources and capabilities (Barney and Clark, 2007; Barney and Hesterly, 2012).

Teece et al. (1997) present the notion of dynamic capabilities, which "continuously create, extend, upgrade, protect, and keep relevant the enterprise's unique asset base" in a changing environment (Teece, 2007, p. 1319). They are mainly significant in rapid or unsettled markets and instrumental in modifying other resources and creating value (Eisenhardt and Martin, 2000). Dynamic capabilities affect the speed and the degree to which a company's resources can match up the changing environment in order to produce sustained positive returns (Teece, 2012). Examples of dynamic capabilities may be product and service development routines, resource allocation procedures, and knowledge creation processes (Kozlenkova et al., 2014). Dynamic capabilities can be classified as: sensing, which is the detection, expansion, and evaluation of opportunities with respect to customer needs; seizing, which refers to the utilization of resources to tackle those opportunities while attaining value; and transforming through a continuous renewal of resources (Teece, 2012). A firm's engagement in sensing, seizing, and transforming is key to maintain sustained performance in the market, given the permanent changes in customers, competitors, and technologies (Teece, 2007). What turns 
capabilities into "dynamic" is their proficiency to change the manner by which a company makes its living by rearranging resources and effectively influencing the firm's external environment (Teece, 2007; Helfat and Winter, 2011).

Whereas operational capabilities comprise the basis of the process to complete tasks, dynamic capabilities encompass higher-level activities that allow operational capabilities to achieve larger returns (Teece, 2014). Operational capabilities assist organizations in making their living by efficiently implementing the required routines. Conversely, dynamic capabilities contribute by increasing the productivity of operational capabilities and reshaping resources in volatile settings (Teece et al., 1997; Eisenhardt and Martin, 2000; Winter, 2003; Helfat and Winter, 2011; Teece, 2014). Thus, ordinary capabilities relate to doing things right, while dynamic capabilities relate to doing the right things, timely, while continuously evaluating the business situation and new opportunities.

\section{Interfunctional coordination as a dynamic capability}

Previous research posits that market orientation (Narver and Slater, 1990) is the higherorder construct which has IC as a key component and can be thought as a dynamic capability based on its role in acquiring and using market knowledge and deploying firm resources to create value for both the customers and the company itself (Sett, 2018). Ma et al., (2011) argue that market orientation constitutes a culture that nurtures dynamic capability to enable a firm to react to the changing external environment. Moreover, Menguc and Auh (2006) use a resource-based view to examine the competitive value of market orientation from the perspective of a firm's internal capabilities.

In this research, IC is proposed to be considered as a dynamic capability when managed adequately. Narver and Slater (1990) evidently consider the management of resources and a coordinated response to market developments as integral parts of IC, as they describe its purpose as the "coordinated utilization of company resources or to integrate effectively, as well as adapt as necessary, its entire human and other capital resources in its value creation efforts." (Narver and Slater, 1990, p. 22). Likewise, Auh and Menguc (2005) argue that IC is similar to a dynamic capability, as it expedites the conversion of different cognitions into a cohesive and resourceful social capital. Therefore, IC can be considered an organizational capability, as it constitutes a routine in the form of learned behaviors that are founded in part in tacit knowledge, expected to contribute to specific 
organizational outputs (Winter, 2003). The challenge is to develop IC as a dynamic rather than an operational capability, in order to exploit its social complexity and strategic potential, making it much more difficult to imitate (Möller and Svahn, 2003; Barney, 2014; Vesalainen and Hakala, 2014). Following Teece (2012), we expect IC to have a major role in sensing market opportunities and threats, seizing those opportunities while offsetting threats, and transforming the required resources to adjust to the external environment.

A central theoretical premise of this research is that IC will constitute, in fact, a dynamic capability only if it manages to integrate all the internal resources and processes of the firm. Previous research suggests that resources are harder to imitate and more likely to create a competitive advantage when configured and integrated in a firm-specific way (Barney, 1991; Coreynen et al., 2017). Furthermore, companies need to constantly balance the front-office customization with the back-office production and delivery as part of a hybrid offering capability (Ulaga and Reinartz, 2011). From the perspective of marketing dynamic capabilities, Falaska et al. (2017) indicate that what allows an organization to generate customer value and attain a competitive advantage is the dynamic integration of marketing-related assets and knowledge and that a key success factor is the promptness of cross-functional processes reaction to market changes.

\section{Methodology}

The primary purpose of this study is discovery, not hypothesis testing and not trying to control variables, but to discover them (Corbin and Strauss, 2008). Therefore, this research was conducted using a qualitative approach. This has been done with the design and integration of three different studies. A grounded theory method (GTM) was adopted using the data coming from different sources (Glasser and Strauss, 1967) to inductively explore how the IC occurs, allowing themes to emerge from an inductive perspective and to avoid preconceived ideas with an open approach (Goulding, 2002). There are three areas that are of special interest when planning a qualitative study: the activity protocol, the sampling of participants, and the management and analysis of data (Creswell, 2009). Each of these areas is carefully addressed in this section.

\section{Research context and sample}


The context of this study is based on Spanish firms operating in B2B. In total, 45 participants were selected for this research: 5 for the focus group; 31 for in-depth interviews, and 9 for the online focus group. Top executives were selected in their capacity of key informants for their respective firms and all of them participated only in one of the three studies. Most of the firms were large enterprises with more than 50 million euros of annual turnover and more than 250 employees, representing different sectors (See Table 2 in Appendix).

\section{Design of the studies and data collection}

The data were collected using different sources in order to give more consistency to the research (Yin, 2015). Study 1 consisted on a face-to-face focus group to identify the main themes, drivers and actors that would be investigated in detail in the Study 2, involving in in-depth interviews.

Initially, only the first and second studies were planned, but, following a process of dialogue with data, and, as some surprising results emerged from the Study 2 that should not be left unanswered, then a third study was conducted consisting of an online focus group.

The selection process of participants and firms for the three studies was guided assuring the level of saturation (Corbin and Strauss, 2008) regarding the sectors to be represented, the different departments and the job positions of participants. These studies were coordinated and integrated. The exploratory approach has been successfully implemented in prior B2B marketing research (e.g., Komulainen, 2014).

NVivo 11 was the software used to conduct the analysis of the qualitative data produced in the in-depth interviews. NVivo is a computer-assisted qualitative data analysis software (CAQDAS) extensively used in qualitative research (Schmieder, 2014). CAQDAS is a convenient solution to manage and meticulously work with the enormity of information that is generally produced in qualitative research (Talanquer, 2014).

\section{Study 1: Focus group}

The focus group is a type of group discussion frequently used in marketing whose main contribution is not the particular opinion of participants, but the insights that emanate 
from their discussion about one very specific topic (Flick, 2018). A key aspect of a focus group is the researcher's role in facilitating the discussion, but not explaining or interpreting the expressed ideas (Neuman, 2014). In order to fully exploit a focus group as a qualitative technique, it must count on heterogeneous participants (Flick, 2018), but still belonging to a common population (Bell, 2014). Another requirement is that only a limited number of topics should be discussed (Neuman, 2014), otherwise the depth in which they are discussed would not be enough.

Following these criteria, a pool of 12 potential participants representing different sectors and managerial positions were initially pre-selected. After internal discussion, 7 were invited to participate and 5 of them agreed and took part in the focus group. The moderator of the discussion used open-ended questions to encourage detailed responses to give more discretion to participants (Charmaz, 2006). The focus group was aimed at grasping the general idea about IC that these practitioners had and discuss which themes, drivers and actors should be considered when studying the concept of IC. Therefore, the results of this first qualitative activity were intended to provide inputs to the following stages of this research rather than in extracting significant conclusions regarding the aim of the research itself.

\section{Study 2: In-depth interviews}

The second stage of this research aimed to explore the relationships between the central themes identified in the previous focus group with the main drivers identified and the enablers and barriers. For this purpose, participants were recruited through personal invitation by the authors of this research. Initially 45 top business executives representing B2B companies were approached: 14 of them politely declined to participate for personal reasons and 31 finally participated, being 24 from large enterprises and 7 from small and medium-sized enterprises (SMEs). These top executives came from diverse sectors, including consumer goods and distribution (28\%); technology (22\%); professional services (10\%); utilities (10\%) and others (see Table 2 in Appendix). Regarding the experience: $93 \%$ of participants had more than 15 years of professional experience and $70 \%$ of the total had been working in the current company more than five years. In relation to their roles: 25\% were CEOs or general managers; 25\% were in Marketing or Sales; $10 \%$ in technical positions; $10 \%$ in operations; $10 \%$ in Human Resources (HR) and the rest in other roles. Most firms (77\%) were large firms with an annual turnover of more 
than 50 million euros, and with more than 250 employees. The interviewers were the authors of this research. The interviewers assured the participants that their responses would remain anonymous and that the results would be used only for academic research purposes. Each of the researchers prepared independently a list of questions that were circulated to all members of the research team. After academic discussion, a list of questions was selected. Most of the questions fall into three main areas: a) themes found in Study 1; b) drivers as barriers or enablers and c) actors. A few target questions were developed for each one of the three areas. Before starting the interviews, the interviewers revised the protocol with the questions and agreed on the structure to gain consistency. They also agreed on the measures to ensure a minimal influence of the interviewer to avoid any possible bias or guidance towards any kind of responses.

The main data were comprised by the insights from the interviews to practitioners. Once the interviews were transcribed and uploaded to NVivo, 2 researchers conducted the codification process in a simultaneous and iterative way. A first tree of codes was created according to the structure of the interview. Then, other several codes were created as the codification progressed. This process totaled 61 codes in 3 hierarchical levels of codes. Finally, a last revision of a third researcher helped to merge and split some of the codes in order to further facilitate the discussion and extraction of findings and conclusions.

\section{Study 3: Online focus group}

After surprising and contradictory findings from Study 2, using back and forth dialogue with a data abductive approach (Dubois and Gadde, 2002) and with the purpose of gaining clarification, an online focus group was designed, which is expected to perform with the same validity as face-to-face interactions (Reid and Reid 2005). In particular, this data collection method was chosen to allow quick exploration of themes to secure access to certain populations of interest which are difficult to reach and schedule at the same time in the same physical location (Stewart and Shamdasani, 2017). Furthermore, the potential anonymity of virtual groups may make participants more willing to participate and express themselves with more sincerity and fewer precautions (Stewart and Shamdasani, 2017). According to Stewart and Shamdasani (2017), online focus groups can be classified in three categories: asynchronous groups, synchronous groups, and groups in "virtual worlds". For the purpose of this study, asynchronous approach was chosen and it was designed over a period of time of one week. 
A total 9 participants were selected based on their expertise on the themes to be discussed. Padlet was the online tool that was used that also allows discussion threads. This is a free platform that guarantees anonymity. Participants registered in the forum following the link that they received individually by invitation and which was coordinated by a skilled moderator. The online focus group was designed to address only the surprising findings of the Study 2 that were related to digitalization in particular: a) how digitalization was contributing to IC; b) the negative effects of digitalization.

\section{Results and Discussion}

\section{Results and discussion from the Study 1: Focus group}

The main findings were about the themes, drivers, and actors that were more relevant regarding IC according to the participants (see Table 1) and that should be addressed in a further study with in-depth interviews. The themes proposed were: information exchange; collaboration and best practices. The drivers identified were: digitalization, technology, processes, culture, alignment of interests, agility, attitude, motivation, and empowerment. Finally, the main actors involved were: employees, managers, and customers.

Regarding the themes, the first one proposed by $80 \%$ of participants was information exchange. One top executive expressed: "People tend to keep the information for themselves, and this limits the possibilities to coordinate different departments. Undoubtedly, information exchange should be a topic to explore within the study of interfunctional coordination." Such statement was developed by several participants who expressed that "information exchange should be covered by an appropriate collaboration amongst departments." After detailed discussion about the importance of collaboration, most of them agreed that this should be the second theme. In a very conciliatory manner, there was a participant who said that studying IC should not be only about information exchange or collaboration, but mainly about the identification of those "best practices that really work in the field." Again, there was a moderated discussion and, finally, all agreed that the third theme to be investigated was the identification of best practices.

In relation to the drivers to be studied in depth, participants highlighted the following: digitalization, technology, processes, culture, alignment of interests, agility, attitude, motivation, and empowerment. The research team, a posteriori, classified these drivers into three levels: strategic level (technology, processes, digitalization); organizational 
level (culture, alignment of interests, agility) and individual level (attitude, motivation and empowerment) (See Table 1).

For the strategic level, digitalization was considered by participants as the main driver for developing IC. The second driver was technology, which was understood by them as the tools used in companies to facilitate the digitalization and IC in general. Both drivers were mentioned many times as going hand-in-hand. In that sense, one participant said: "technology and digitalization are both important for IC, the former because it provides the tools you need, the latter because the main part is how you use those tools and how much you are able to exploit the information and the advantages of that coordination." The role of processes was pointed out as another important strategic driver by practitioners: "it would be interesting to see how and what the processes should be in order to deploy the interfunctional coordination in our company."

For the organizational level, all the participants agreed on the importance of culture to understand the potential coordination of the different functions in their companies. One participant wondered: "How do you want to improve your interfunctional coordination if you don't have the culture to do so?" Another organizational driver considered was the alignment of interests and goals. Regarding this, one participant manifested: "if everyone works with the same goal, they will try to be coordinated." The last organizational driver was the agility of the organization, as it helps to better respond to the customer's needs in coordinated manner.

For the individual level, participants identified the attitude, motivation, and empowerment as main drivers. One of them indicated: "motivated employees and with the adequate attitude are critical in our departments to see the results of their coordination." However, this assertion was nuanced by another participant: "In addition to attitude and motivation, I would also add the level of empowerment you provide to your employees."

The focus group continued with the discussion about the role of the different actors that are involved and lead the IC. The 5 participants agreed that all employees of the firm should be engaged in the coordination amongst departments. However, 3 of them insisted in the importance of the role played by the company's top management team. As expressed by one: "you can have the most engaged employees, but without the compromise and involvement of the top management, my experience is that the 
coordination never happens. This might sound obvious but I have seen this too many times. " Surprisingly, one practitioner focused the debate on the customers too: "in certain B2B industries, customers can also play a key role in your coordination, why? Because they are the ignition and the end of any activity your company undertakes and this necessarily involves different departments."

Table 1: Findings from the focus group: main themes, drivers and actors in IC.

\begin{tabular}{|c|c|c|}
\hline IC-related themes & IC Drivers & IC Actors \\
\hline Information exchange & $\begin{array}{c}\frac{\text { Strategic level }}{\text { Digitalization }} \\
\text { Technology } \\
\text { Processes }\end{array}$ & Employees \\
\hline Collaboration & $\begin{array}{c}\text { Organizational } \\
\text { level } \\
\text { Culture } \\
\text { Alignment of } \\
\text { interests } \\
\text { Agility }\end{array}$ & Managers \\
\hline Best practices & $\begin{array}{c}\text { Individual level } \\
\text { Attitude } \\
\text { Motivation } \\
\text { Empowerment }\end{array}$ & Customers \\
\hline
\end{tabular}

Source: Own elaboration.

A last conclusion from the focus group was regarding the role that each driver and actor could play in the IC. According to participants, it would be of interest to see whether each driver serve in reality and practice as an enabler or as a barrier for IC. This is one of the aims of the Study 2 conducted by in-depth interviews.

\section{Results and discussion from Study 2: In-depth Interviews}


Based on the findings from Study 1, the second qualitative study consisted of a series of in-depth semi-structured interviews with practitioners. The 31 participants were interviewed about: (1) the current status of IC in their companies and industries, in general and, in particular, in relation to the three main themes that were identified in the focus group (information exchange; collaboration between departments; best practices); (2) the different drivers (digitalization, technology, processes, culture, alignment of interests, agility, attitude, motivation, empowerment) and about the actors (employees, managers, customers) and (3) the role of each of these elements played as enabler or barrier.

\section{Current situation of IC and main themes}

One of the findings is regarding the level of IC in their firms: most participants manifested that the level of IC in their firm is adequate, but only a few regarded it as excellent. However, 3 interviewees acknowledged that, in their firms, there is a lot of room for improvement. Three main themes were explored: a) exchange of information; b) collaboration and c) best practices of IC.

\section{a- Exchange of information}

Exchange of information was the first theme identified. One of the main findings is that only 3 interviewees indicated that the level of information exchange in their firms was very low. All the other participants acknowledged that, in their firms, there was a good level of information exchange. Half of the comments referred to the benefits of the exchange of information. Another finding is that there are two main benefits of information exchange: agility and a better customer orientation. It is important to highlight that, for $60 \%$ of respondents, the motivation to share information is mainly reactive and not proactive: "in our firm we share information in a very reactive way. It means that we only share when it is strictly needed and when we don't have any other alternative. It we were more proactive sharing information, I am sure that the firm would be more efficient and profitable."

\section{b- Collaboration}

Collaboration between business functions was another key theme identified. One of the findings was that nearly $50 \%$ of participants indicated that those business functions which 
have a higher level of mutual collaboration are Marketing and Sales. A quarter of participants mentioned other departments, such as Operations and After-Sales, but also mentioned Marketing and Sales in their comments. For the other quarter of participants there was a variety of business units, such as Finance, HR and IT. Based on the interviews, it was confirmed that those areas that are closer to the customers are more engaged in collaboration activities, not only amongst themselves, but with all business functions, and, therefore, in IC, because these are really concerned about giving solutions. In that sense, one indicated: "It is obvious that those that, at some point, see the face of the customer are more open to collaborate that those that never meet with the customer and are more focused on their internal processes and rules than in delivering a real solution to the customer." However, it was not clearly stated which department should lead the IC process. Most interviewees agreed that the IT department has to be subordinated and provide service to all other departments, but not the other way around. In regard to IT, $25 \%$ of participants complained about its power, such as: "in my firm IT has too much power and this doesn't make sense. Sometimes it seems that we work for them when in fact it is them who should work for us." The departments with lowest level of collaboration were Finance with Marketing and IT with Marketing. In relation to IT, one participant said: "I have to reckon that IT is somehow a dark area in our company and we doubt whether they don't collaborate because they can't or just because they don't want to. The most frequent excuse is that they are busy. They hide themselves in a cryptic language with their own jargon. It is common to hear from their lips that something technically can't be done. Definitely, the IT Department doesn't have a reputation of being collaborative."

Other findings were regarding the main reasons for a lack of collaboration: the fact that some departments accumulate too much power and the absence of common activities or projects that affect customers.

\section{c- Best practices}

Best practices in IC was another theme that emerged from the focus group. Interviewees illustrated some of these best practices that improve IC. Processes that facilitate IC and projects in cross-functional teams were mentioned by $60 \%$ as a best practice. This first set of best practices can be categorized as procedural best practices, as they include not only processes and styles of working, but also protocols, written policies, etc. A second 
set of best practices can be categorized as related to communication, such as: internal communication channels, formal meetings; shared information in a systematic way, both horizontally and vertically. A third set of best practices can be categorized as technological solutions, such as: use of video conferences; SharePoint; Cloud solutions; slack; CRM and Apps.

\section{Drivers for interfunctional coordination}

As it was previously explained, this study has categorized the drivers for IC in three levels: strategic, organizational and individual.

\section{Strategic level}

\section{Digitalization}

Digitalization is the main strategic driver according to participants. Digital transformation affects the business environment and IC in particular. Such assertion was expressed by the majority of participants: "Digitalization is part of our culture and raison d'etre of our business." Digitalization plays a key role in IC, as stated by $45 \%$ of participants. However, some acknowledged that digitalization is far from adequate: "Digitalization is important and urgent. We are aware of the long road we have ahead of us, but, unfortunately, day-to-day activities impede us to focus on digitalization." Amongst the specific factors affected by the digitalization in relation to IC, three were highlighted: communications resources, cloud tools and information sharing platforms: "The use of video conferences allows the exchange of information and the communication between employees from different departments in diverse locations"; "In the last four years, the use of a sharing platforms with our sales force teams have facilitated enormously the coordination"; "Having all the information in the cloud and accessible is critical for our coordination."

\section{Technology}

The integration of new technologies was the second driver for IC: "The knowledge and use of technology, as well as understanding the value they provide, is key for the IC success." This value is observed in how technology facilitates the dialogue with 
customers. However, some had the impression that the level of implementation is still too low to really exploit all the advantages of technologies. One practitioner expressed this idea: "We have really advanced technologies, but the challenge is to exploit all the potential they offer."

\section{Processes}

The third driver in IC was the design and implementation of processes that should work as facilitators. This role is played only when they are clearly defined, as manifested by $37 \%$ of the participants: "There are several processes, different policies and responsible positions for the coordination"; "Processes allow the company not to depend on the attitude of employees by determining the expected activities from each participant"; "A smart description of processes can avoid a lot of conflicts of interest."

Additionally, the execution of processes is critical in IC. Processes should flow and improve accordingly as a framework where all activities occur and have an enormous effect on the efficiency: "More and more processes tend to flow smoothly"; "We review the processes from other areas to share experiences and best practices"; "Overlappings and duplications make the coordination of departments difficult."

\section{Organizational level}

\section{Culture}

Culture of collaboration was the first theme identified at organizational level. The main finding is that it is not present in all firms. In fact, $30 \%$ of interviewees stated that there is no collaboration culture in their firm. One of them manifested: "No, indeed we do not have a collaboration culture at all. Individualism, reticence, power struggles and similar dysfunctions are deeply rooted in the culture of this firm. I would dare to say that each department behaves like a taifa ${ }^{1}$ kingdom."

Another third of participants considered that there is a high level of collaboration culture: "Our motto is that we need to behave like a marabunta, because we are like an army of

${ }^{1}$ Taifa kingdoms are the several small states that appeared in Muslim Spain after the disintegration of the Ummayad caliphate. They were characterized by the lack of unity and coordination against the increasing momentum of the Christian reconquest (Encyclopaedia Brittanica, 2019) 
ants and acting that way we become invincible. One ant in her own is not capable of doing anything."

Interestingly, a final group considered that their culture of collaboration is mainly due to the technical nature of their projects and they acknowledged that they incur an opportunity cost. It is very illustrative to read what a general manager explained: "It could be said that there is a culture of collaboration because, given the technical dimension of our projects and services, it would be practically impossible that there was not. However, there is a lot of room for improvement, and it is hard for us to understand the opportunity cost that is incurred precisely because there is no collaboration culture in those areas in which the technical nature does not oblige. I am convinced that, if we were more proactive to collaborate, not only for when we are reactively obligated to them, we would perform much better."

\section{Alignment of interests}

The conflicts of interests between departments have been acknowledged as the main barrier to IC. One manager from banking sector said: "In some banks they create on purpose a culture that lead different business areas to compete between themselves and make it very difficult to collaborate. This competition between business areas may bring future problems to the firm."

With a similar approach, another participant indicated that: "it is frequent that each department has objectives that clearly are the opposite of those from other departments." Likewise, another participant manifested: "The lack of specific incentives to achieve general objectives is a barrier to coordination that facilitates the individual search of individual personal success to the detriment of the common goals of the firm and the fear of reprisals."

A way to minimize the negative effect of contradictory objectives between departments is to set incentives that help to integrate goals. Therefore, a very important enabler of IC is a common strategy for the whole company, integrated by common objectives and rewards focused on priorities: "when objectives are aligned, this facilitates the setting of priorities and synergies that are generated will place the customer at the core of the firm's strategy." Power is another relevant barrier to IC: "some managers do not share information or just share the very least due to the fear of losing their power or influence." 


\section{Agility}

Agility is another enabler of IC: "in our firm, agile methodology is a key element to facilitate coordination and collaboration." Another participant mentioned: "agility reduces substantially waiting times between departments." A third interviewee manifested: "automation of processes improves agility across all functions and has a positive impact on coordination." A last one said: "agility enables us to be oriented to customer needs and provide solutions with positive impact on service quality."

Flexibility is another enabler of IC: "flexibility reduces the number of unnecessary frictions between functions and brings the coordination of work to a state of flow."

\section{Individual level}

\section{Attitude}

The negative attitude of individuals is a barrier to IC: "personal egos and protagonistbased culture are clear barriers that make customer orientation difficult"; "individuals" attitude is the main barrier to coordination." Interpersonal relationships can be another barrier for IC: "a main barrier for the coordination is the lack of interest of people to collaborate due to personal grudges and susceptibilities."

Conversely, one of the main enablers is people's positive attitude. It is paradoxical because they also mentioned that people could be one of the main barriers: "In our firm, recruitment is crucial to assure that we hire people with the best qualities and right attitude."

\section{Motivation and empowerment}

Motivation and empowerment have been considered enablers being particularly important in firms that work by projects. One participant said: "In our firm most of our work is delivered by projects and, for that scenario, having specialized and motivated employees is essential for the success of projects." Another said, in the context of empowerment and projects, that "the sense of belonging is crucial."

\section{Actors in IC}

Three main actors have been identified: a) employees; b) managers and c) customers. 


\section{a- Employees}

Technology and processes in IC are considered useless without involved and motivated employees. In fact, $60 \%$ of participants declared that employees play a crucial role in IC. Regarding employees that are more open to collaborate: "This is a question of attitude and it must manifest by having initiative"; "You have to promote the active participation of your employees avoiding any negative consequence."

Personal relationships can be both formal and informal and facilitate the culture for IC: "Personal relationships influence significantly the coordination amongst departments"; "People are what change the culture."

Some of the participants pointed out employees as being responsible to follow the procedures and to coordinate their functions: "Employees work according to protocols and they have to transmit what comes out from their departments."

\section{b- Managers}

Management teams play the most important role in IC. This was explicitly confirmed by almost all participants. Respondents expressed different reasons: "The general management is responsible for the execution and coordination of opportunities and resources"; "Managers help by promoting the collaboration as a guideline for the company functioning"; "Managers smooth over different visions from different employees and departments."

\section{c- Customers}

There was certain discrepancy about the role that customers can play in IC. On one side, there was the group that did not consider customers as playing a relevant role: "Our coordination is about internal procedures what vaguely go beyond to our customers"; “Customers rarely take part in our processes"; "Customers only collaborate just partially and indirectly."

On the other side, there were several interviewees that saw customers as an important part of IC: "Everything springs from the customer because they generate the information"; "We always define our business plan by collaborating with our customers."

IC is regarded to have many positive consequences for customers. More than $65 \%$ of participants said that IC has a positive impact on customer orientation through these 
actions: agility; customer-centric vision; cost reduction; time saving; setting of priorities based on customers' needs and preferences; customer satisfaction and time to market.

Based on the responses from practitioners, Sales and Marketing are the two departments that must try to better involve the customers in the IC processes. This was asserted by $40 \%$ of participants: "Frequently our customers are forcing us to be coordinated. Or customers are companies and our service is mostly customized. Therefore, they are involved and we are the most interested in having our customers fully engaged."

Co-creation activities appeared to be relevant in the participation of customers: "development of joint growth plans or in a new product development process, whose idea comes from our customers many times." According to 9 participants, it is in the customization of products and services where customers are more involved. Another relevant element of this co-creation process is the collection of customer feedback, which is usually undertaken by means of focus group, interviews, surveys, or B2B meetings.

For $40 \%$ of participants, the main benefit of IC is the creation of synergies with customers that is produced by collaboration of different teams from both their companies and their customers: "The co-creation is attained by collaborating in projects in which business customers obtain synergies that help them to be more efficient in the market."

Given the results and findings from the qualitative interviews, there are several elements that can act simultaneously as enablers and barriers, depending on the orientation they take. Moreover, they proved to be transversal to both actors and factors that take part in IC.

\section{Surprising findings}

Some findings that emerged were considered by the participants as surprising or somehow contradictory with common beliefs. The research team, after careful discussion, identified four: a) negative side effects of digitalization; b) saturation of information; c) work in silos and conflicts of interests and d) lack of integration of customers.

The main negative side effect of digital transformation is that it implies a lower level of human interaction and, therefore, a less intense IC. The digitalization process emerges, therefore, as a critical theme related to IC due to its importance as a critical capability. 
The second theme that had a very important negative side effect came from the saturation of information, as expressed by one of the interviewees. This refers to the excess of information that has the consequence of the lack of capacity to assimilate such information, basically due to the lack of elaborated information. When information is not elaborated, summarized and categorized, it also generates this negative effect of saturation: "some departments purposely inundate other departments with unstructured information and this is used as a smokescreen to distract attention from other relevant aspects."

The third theme was the conflict of interest and the power struggle. This reaches the maximum level when departments start acting independently, which makes impossible any kind of IC. Such situation was coined as taifa kingdoms and represents an emerging theme requiring special attention. More than $40 \%$ of participants in this study mentioned that this situation arises when departments work as silos: "My company is very rooted in a culture that make departments work as silos, with huge personalism and fights for power."

The last theme that requires special attention is the role of customers in IC. Since cocreation activities have proved to be a critical differentiation, it may require further analysis to understand why customers are not involved in the IC for the B2B companies investigated in this study.

The negative effects of digitalization that were mentioned before as the first surprising finding were investigated in Study 3 (online focus group).

\section{Results and discussion from Study 3: Online focus group}

The nine participants in the online focus group discussed about how digitalization was helping IC and also about the negative effects of digitalization.

In relation to the role of digitalization and IC, $75 \%$ of participants agreed that their companies are addressing digitalization as a means for improving their performance by staying competitive, reducing costs and optimizing operations. However, despite the importance, most of them indicated that they are not managing the digitalization process adequately as the daily urgent matters prevent them from focusing on it. In that sense, 
$80 \%$ clearly indicated that digitalization is helping them mainly in three areas: a) customer relationships and b) evaluation of employees' performance and talent management; c) agility respond to market opportunities. One participant indicated that digitalization was helping with talent management: "Digitization allows talent to be ubiquitous, developing multidisciplinary organizations. The digital tools favor the connection, but they lose personality due to the lack of approach and can make the workers always to be connected online."

Regarding the negative effects of digitalization in their firms, four main concerns were identified and are also illustrated with their comments: a) investment in digitalization is expensive and ROI is not always positive due to the poor use of digital resources: "we invest a lot of money in digitalization but, before investing, we rarely ask ourselves if we can make the most of these tools. When we implanted the ERP and a CRM we assumed that everyone knew how to use them and the fact is that we are only using $30 \%$ of all the potential of these tools"; b) the rhythm of digital transformation is not followed by the preparation of employees and a coherent talent management and recruitment strategy: "we are overwhelmed by the speed of digitalization and we are not recruiting correctly and the training strategy is clearly insufficient: this generates permanent frustration in our staff and in the top management"; c) all the possibilities of digitalization frequently generate misuse of digital tools causing harm to customers: "due to the potential of digitalization we are promoting in our company what I call a mad effort to customize the solutions to the customer and this often backfires on us, as customers don't want too much invasion of their privacy"; d) digitalization is also causing a risk of depersonalization: "in the past, before all this hysteria of digitalization, we knew our customers and they knew us. We are in a B2B environment where personal relations are crucial and now, with the automated telephone systems and with the Apps, it seems that we are hiding ourselves behind the digital word and we are pushing our customers to the impersonal world of binary zeros and ones."

\section{General discussion: digitalization capability as main driver for IC}

It is interesting to understand how digitalization can contribute to IC in light of the conceptual framework of dynamic capabilities and based on some of the results of the three studies of this research. 
One participant said: “digitalization helps us through the interfunctional coordination to execute the strategy and integrate all resources." This confirms Resource-based theory (RBT) that considers organizations as bundles of resources and capabilities that allow them to build and execute their strategy (Barney and Arikan, 2001). Another participant indicated: "we need to be agile with the digital transformation, otherwise we will never meet our customers' needs. Digitalization is helping us to coordinate resources and to integrate business processes." This corroborates the findings of Crittenden et al. (2019), in the context of dynamic capabilities that claim that managers need to be digitally agile and take advantage of customers' digital expectations.

A senior executive manifested: "through digitalization, we have been able to multiply by three times our ability to make the most of each and every one of the assets we have in this company." This is interesting in light of Teece et al. (1997) who presented the notion of dynamic capabilities, which continuously create, extend, upgrade, protect, and keep relevant the enterprise's unique asset base.

Another relevant finding about digitalization in the context of IC is the increase of the agility in giving solutions to customers and, consequently, a successful customer orientation. The increase of speed fits with the assumption that dynamic capabilities affect the speed and the degree to which a company's resources can match up the changing environment in order to produce sustained positive returns (Teece, 2012). In that sense $80 \%$ of participants manifested that digitalization has helped them to increase the speed. To illustrate this idea, one participant said: "we could never imagine that the digital transformation of our firm could bring us the speed of light: our customers really value the change and the positive consequences of our increased agility."

"Digitalization is helping us with the design of processes and services" said one participant, supporting Kozlenkova et al. (2014) who suggested product and service development routines, resource allocation procedures, and knowledge creation processes as possible examples of dynamic capabilities.

Sensing is one of the elements of dynamic capabilities (Teece, 2012), which refers to the detection, expansion, and evaluation of opportunities with respect to customer needs. Regarding sensing, $40 \%$ participants indicated that digitalization is helping them to increase the level of IC in order to evaluate customer needs. To illustrate this, one participant said: "the digitalization of the main processes and tasks of our firm is helping 
us to join and integrate efforts to listen and understand what our customers need and want. This identification is becoming more agile and personalized."

Seizing refers to the utilization of resources to tackle those opportunities while attaining value (Teece, 2012). In that sense, $60 \%$ of participants indicated that digitalization is contributing to increase the capacity of following opportunities by means of IC. One comment illustrates this: "digitalization has meant an internal revolution in the way we work now in our firm. We collaborate with higher coordination and this allows us to take advantage of the business opportunities by the optimization of all functions of the firm."

Transforming represents the continuous renewal of resources (Teece, 2012). For 30\% of participants, digitalization is helping them to take control over other activities and to renovate them when needed, in line with the assumption that dynamic capabilities govern other organizational activities (Teece, 2014). One of the participants indicated: "digitalization allows us to make changes in the way we operate and to restructure quickly our resources to meet the needs of our customers." This is also coincident with the vision that what turns capabilities into "dynamic" is their proficiency to change the manner by which a company makes its living by rearranging resources and effectively influencing the firm's external environment (Helfat and Winter, 2011).

\section{Conclusion}

\section{Theoretical implications}

This research contributes to the extant literature in B2B marketing in different ways.

First, this study develops the conceptualization of IC as a dynamic capability. Auh and Menguc (2005) proposed the consideration of IC as dynamic capability and now this paper advances that line of research in several areas. One is the identification and categorization of three types of drivers for IC: a) strategic (digitalization, technology, processes); b) organizational (culture, alignment of interests, agility), c) individual (attitude, motivation, empowerment). Another one is the identification and analysis of the main actors involved in IC: employees, managers and customers and their different roles and contributions to IC. Furthermore, the main themes related to IC have been identified: information exchange, collaboration and best practices, which have been analyzed and discussed in depth. Similarly, regarding the conceptualization of IC, the main barriers and enablers have been identified. A novelty of this conceptualization is the proposal of some conditions to consider IC as a dynamic capability. This study suggests that IC should be 
only considered as a dynamic capability if at least certain conditions are met: 1) IC needs to clearly contribute in a very specific way to sensing the opportunities for customers, seizing and transforming firm resources to provide solutions to customers (Teece et al., 1997; Eisenhardt and Martin, 2000; Winter, 2003; Helfat and Winter, 2011; Teece, 2014); 2) it is a basic requirement to assure that IC is giving support to the main operational capabilities (Teece, 2012); 3) it is essential that IC integrates the main functions of the firm to be customer-oriented as dynamic capabilities govern other organizational activities (Teece, 2014).

Second, this research has empirically shown that digitalization is considered by participants in this study as the main strategic driver for the implementation of IC in B2B settings, as digitalization will contribute to the purpose of the dynamic capabilities, which is to achieve congruence with customer needs and with technological opportunities (Teece, 2014), digitalization clearly being a technological opportunity. This is another distinctiveness of this study with a rich contribution to the B2B literature, in particular about the role of digitalization in IC. Moreover, digitalization is a driver that should facilitate firms to meet the previous mentioned conditions to make IC an authentic dynamic capability.

\section{Implications for practice}

This study contributes with several managerial implications.

First, managers should be aware that, although digitalization has undeniable benefits for firms, it is not without difficulties and it also has risks and also possible negative side effects. In particular: a) investment in digitalization is expensive and ROI is not always positive due to the poor use of digital resources; b) the rhythm of digital transformation is not followed by the preparation of employees and the expected coherent talent management and recruitment strategy: c) the huge possibilities of digitalization frequently generate misuse of digital tools causing harm to customers; d) digitalization is also triggering a risk of depersonalization. These four concerns can be addressed with a more conscious investment policy, with training and in-depth analysis about the impact of their decisions on customers. This can be integrated within the development of technological knowledge (Argyres and Silverman, 2004). 
Second, in light of the findings of Maltz et al. (2001) cross-functional team use reduces perceptions of rivalry among functional units. Practitioners could create cross-functional teams to mitigate the tendency of silos and their negative effects. Managers should try to avoid silos in their firms, because silos limit the sort of cross-functional dialogue and learning that creates novel ideas, and, thus, slows adaptation (Day, 2011). Instead of focusing on the risks of working in silos per se, managers could develop metrics to lead the organization through incentives and common rewards to promote IC in an effective way that can be observed in specific behaviors and processes.

Third, managers should elaborate the information before internal circulation, to avoid the saturation effect. In fact, regarding the excess of information, it was discovered that the rapid flow of information from different business units makes it difficult to process the relevant information and to make decisions, confirming previous studies (Eppler and Mengis, 2004; Klingberg, 2009).

Fourth, managers should raise awareness about the advantages of collaboration. All actors need to recognize those benefits because, if they are not evident to the actors, then collaborative activity is unlikely to happen (Kleinaltenkamp et al., 2012). In that sense, firms can create specialized interfunctional teams for the implementation of digitalization strategies. Those teams, in order to be effective, need: full support from top management; clear processes that facilitate the integration of all resources, human and technological; and a clear focus on the integration of customers in order to co-create solutions. Another way of advancing in collaboration is by promoting the sharing of best practices about digitalization and IC within the firm and also with their own business customers.

Fifth, practitioners could establish management policies that facilitate the design and implementation of clear processes (vom Brocke, Zelt, \& Schmiedel, 2016) that guarantee that those businesses functions that need to be involved in a decision that affects customers should be involved and, what is more important, that these processes prevent some individuals or units to accumulate power working as silos, and, instead, to crosspollinate digital ideas from other industries, companies or business lines (Crittenden et al., 2019). In particular, a common strategy for the whole company integrated by common objectives and rewards will help IC. 
Sixth, managers need to be digitally agile and take advantage of customers' digital expectations (Crittenden et al., 2019) and be aware that digital transformation is not about technology, but about strategy (Rogers, 2016).

Finally, in order to deal with barriers and with enablers, we offer some recommendations for practitioners: 1) design and implement specific processes for IC; 2) combat silos, as they are a source of negativity, power and lack of collaboration; 3) top managers need to clearly define a digital strategy that supports IC; 4) define common reward systems with shared goals between different business functions to mitigate the tendency to work in silos and to generate conflicting goals.

Setting boundaries between business functions makes no sense. Marketing's role in B2B transactions should help to integrate all the firm's functions in order to create, co-create and deliver customer value. This research shows that reward systems and the creation of cross-functional teams will facilitate a high level of IC.

\section{Limitations and future research}

One limitation comes from the fact that the findings of this study have been obtained from the firm executives' perspective, but not from customers' perspectives. It can be relevant for future research to incorporate the customer's vision. A second limitation is that, in Study 2 (in-depth interviews), $77 \%$ of the firms represented were large enterprises while only $23 \%$ were SMEs. It would be convenient in future studies to put more focus on understanding IC in SMEs. A third limitation could come from the sectors represented in the study. Although there are different sectors, two sectors have a higher representation: consumer goods and distribution (38\%) and technology (22\%). A fourth limitation is regarding the departments represented in Study 2: although most of the departments have a good representation, such as General Management (25\%), Marketing and Sales (25\%), HR only has $7 \%$ of participants. It was difficult to get more participants from HR and this could be enhanced in future studies.

Regarding future areas of research, as a result of the findings and discussion of this study, more efforts are needed in order to understand the role of digitalization in IC in a B2B context. This could include developing research avenues that investigate: a) how digitalization is helping to a better understanding of customers' needs; b) to what extent 
digitalization is helping to seize marketing opportunities; c) how digitalization can be an effective driver to transform opportunities into solutions to customers and contribute as an enabler for value co-creation (Lenka et al., 2017).

Another future area of research is to investigate how digitalization as a strategic driver can enhance IC as a dynamic capability in order to improve customer orientation (HennigThurau, 2004; Morales Mediano and Ruiz-Alba, 2018; González-Porras et al., 2019).

With Artificial Intelligence (AI) everything has changed totally. The concept of collective intelligence is giving a new and interesting perspective to business management. Future studies could focus on how AI and machine learning are affecting IC in industrial marketing and how the incorporation of smart technologies to human processes are facilitating the emergence of new and more powerful forms of collaboration, not only between humans, but also between computers and individuals (Malone, 2018).

Finally, there is a need to conduct more quantitative studies about IC in general and also, in particular, in business markets. There is a lack of survey instruments, as the most frequent used are too short and, when items are analyzed, they do not always measure IC as they contemplate other elements that should not strictly be considered as IC. Therefore, reliable questionnaires should be developed based on consistent theoretical frameworks.

Sharing information and creating knowledge through IC are crucial activities to keep firms competitive. This can be bolstered through digitalization, but this is not enough as IC should also be considered as a dynamic capability that integrates the customer in the design and the delivery of solutions for them.

IC can present problems as it requires considerable amount of time invested in meetings, sharing information and waiting for the authorization of other units. This can be perceived as a waste of time or an unnecessary process that will cause loss of agility and speed to market. IC can lead some units to lose power or control against others. The lack of IC can also generate conflicts amongst individuals and even create conflicting goals. However, despite those potential problems, the coordination of interfunctional interdependency can produce many benefits, as it allows a more efficient use of all resources and capabilities of the firm to create superior value to customers. Also, IC can facilitate gaining access to 
tacit knowledge exchange between Marketing, Sales and other business units (Arnett and Wittmann 2014) that can be dispersed across all functions of the firm.

These research avenues could help to consequently shed more light on IC as a priority for the top managers' agendas in becoming a basic element for business success. Instead of doing only things right, IC, as a dynamic capability, could lead to doing the right things (Teece, 2014).

\section{References}

Aaker, D. A. (2009), Spanning Silos. Boston: Harvard Business School Press.

Altinay, L., (2010), "Market orientation of small ethnic minority-owned hospitality firms”, International Journal of Hospitality Management, Vol. 29 No. 1, pp.148-156.

Amit, R. and Schoemaker, P. J. H. (1993), "Strategic assets and organizational rent. Strategic Management Journal”, Vol. 14 No. 1, pp.33-46.

Argyres, N. S., and Silverman, B. S. (2004). R\&D, organization structure, and the development of corporate technological knowledge. Strategic Management Journal, 25(8-9), 929-958.

Arndt, A. D., Karande, K., and Landry, T. D. (2011). "An examination of frontline crossfunctional integration during retail transactions", Journal of Retailing, Vol. 87 No.2, pp.225-241.

Arnett, D.B. and Wittmann, C.M., (2014). "Improving marketing success: The role of tacit knowledge exchange between sales and marketing", Journal of Business Research, Vol. 67 No. 3, pp.324-331.

Auh, S. and Menguc, B. (2005), "Top management team diversity and innovativeness: The moderating role of interfunctional coordination", Industrial Marketing Management, Vol. 34 No. 3, pp.249-261. 
Barney, J. (1991), "Firm resources and sustained competitive advantage", Journal of Management, Vol. 17 No. 1, pp.99-120.

Barney, J. B. (2014), "How marketing scholars might help address issues in resourcebased theory", Journal of the Academy of Marketing Science, Vol. 42 No. 11, pp.24-26. Barney, J. B. and Arikan, A. M. (2001), "The resource-based view: Origins and implications", in M. A. Hitt, R. E. Freeman, and J. S. Harrison (Eds.), Handbook of strategic management (pp.124-188). New York, Wiley.

Barney, J. B. and Clark, D. N. (2007), Resource-based theory: Creating and sustaining competitive advantage. Oxford University Press on Demand.

Barney, J. and Hesterly, W. (2012), Strategic management and competitive advantage: Concepts and cases (4th ed.). New Jersey: Pearson.

Charmaz, K. (2006). Constructing Grounded Theory: A Practical Guide Through Qualitative Analysis. Thousand Oaks, CA: Sage Publications.

Bell, J. (2014). Doing Your Research Project: A guide for first-time researchers. Open Berkshire: University Press.

Chen, Y. C., Li, P. C., and Lin, Y. H. (2013). "How inter-and intra-organisational coordination affect product development performance: the role of slack resources", Journal of Business \& Industrial Marketing, Vol. 28 No. 22, pp.125-136.

Coreynen, W., Matthyssens, P. and Van Bockhaven, W. (2017), "Boosting servitization through digitization: Pathways and dynamic resource configurations for manufacturers", Industrial Marketing Management, Vol. 60, pp.42-53.

Corbin, J., and Strauss, A (2008), Basics of qualitative research. Techniques and procedures for developing grounded theory. Thousand Oaks, CA: Sage Publications.

Creswell, J. W. (2009). Research Design: Qualitative, Quantitative, and Mixed Methods Approaches (3rd ed.). Thousand Oaks, CA: Sage Publications.

Crittenden, Andrew B., Victoria L. Crittenden, and William F. Crittenden (2019), "The digitalization triumvirate: How incumbents survive." Business Horizons, Vol 62, pp.259266.

Day, G. S. (1994). The capabilities of market-driven organizations. Journal of Marketing, 58(4), 37-52.

Day, G. S. (2011), “Closing the marketing capabilities gap”, Journal of Marketing, Vol. 75 No. 4, pp.183-195. 
Defee, C. and Stank, T. P.(2005), “Applying the strategy-structure-performance paradigm to the supply chain environment", The International Journal of Logistics Management, Vol. 16 No.1, pp.28-50.

Deng, S., and Dart, J. (1994), "Measuring market orientation: a multi-factor, multi-item approach", Journal of Marketing Management, Vol. 10 No 8, pp.725-742.

De Luca, L. M., \& Atuahene-Gima, K. (2007). Market knowledge dimensions and cross-functional collaboration: Examining the different routes to product innovation performance. Journal of Marketing, 71(1), 95-112.

Dubois, A., and Gadde, L. E. (2002), "Systematic combining: an abductive approach to case research", Journal of Business Research, Vol. 55 No 7, pp.553-560.

Eisenhardt, K. M. and Martin, J. A. (2000), "Dynamic capabilities: What are they?", Strategic Management Journal, Vol. 21 No. 1, pp.1105-1121.

Encyclopaedia Britannica (2019), "Taifa - Spanish history - Britannica”, available at: https://www.britannica.com/topic/taifa (accessed 21 March 2019).

Enz, M. G., and Lambert, D. M. (2012), "Using cross-functional, cross-firm teams to cocreate value: The role of financial measures", Industrial Marketing Management, 41, pp.495-507.

Eppler, M.J. and Mengis, J., (2004). “The concept of information overload: A review of literature from organization science, accounting, marketing, MIS, and related disciplines", The information society, Vol. 20 No. 5, pp.325-344.

Falasca, M., Zhang, J., Conchar, M. and Li, L. (2017), "The impact of customer knowledge and marketing dynamic capability on innovation performance: an empirical analysis", Journal of Business \& Industrial Marketing, Vol. 32 No. 7, pp.901-912.

Flick, U. (2018). An introduction to qualitative research. Sage Publications Limited.

García Rodríguez, N., José Sanzo Pérez, M., and Trespalacios Gutiérrez, J. A. (2007), "Interfunctional climate and a new product performance: dependence as a moderator", Journal of Business \& Industrial Marketing, Vol. 22 No. 7, pp.459-473.

González-Porras, J., Ruiz-Alba, J., Rodríguez-Molina, M.A., and Guzmán-Parra; V.F (2019), "International management of customer orientation", European Journal of International Management. DOI: 10.1504/EJIM.2020.10022183 [In Press].

Glasser, B. G., and Strauss, A. L. (1967). The development of grounded theory. Chicago, IL: Alden.

Goulding, C. (2002). Grounded theory: A practical guide for management, business and market researchers. Sage. London. 
Gouthier, M. and Schmid, S. (2003), "Customers and customer relationships in service firms: The perspective of the resource-based view", Marketing Theory, Vol. 3 No. 1, pp.119-143.

Helfat, C. E. and Peteraf, M. A. (2003), “The dynamic resource-based view: Capability lifecycles", Strategic Management Journal, Vol. 24 No. 10, pp.997-1010.

Helfat, C. E. and Winter, S. G. (2011), "Untangling dynamic and operational capabilities: Strategy for the (n)ever-changing world", Strategic Management Journal, Vol. 32 No. 11, pp.1243-1250.

Hennig-Thurau, T. (2004), “Customer orientation of service employees: Its impact on customer satisfaction, commitment and retention", International Journal of Service Industry Management, Vol. 15 No. 5, pp.460-478.

Javalgi, R.G., Hall, K.D., and Cavusgil, S.T. (2014), "Corporate entrepreneurship, customer-oriented selling, absorptive capacity, and international sales performance in the international B2B setting: Conceptual framework and research propositions", International Business Review, Vol. 23 No. 6, pp.1193-1202.

Johnston, W. J., \& Bonoma, T. V. (1981), “The buying center: Structure and interaction patterns", Journal of Marketing, Vol. 45 No. 3, pp.143-156.

Kennedy, K. N., Goolsby, J. R., and Arnould, E. J., (2003). "Implementing a customer orientation: Extension of theory and application", Journal of Marketing, Vol 67 No. 4, pp.67-81.

Kohli, A. K., and Jaworski, B. J. (1990), "Market orientation: the construct, research propositions, and managerial implications", Journal of Marketing, Vol. 54 No 2, pp.1-18. Kleinaltenkamp, M., Brodie, R. J., Frow, P., Hughes, T., Peters, L. D., and Woratschek, H. (2012), "Resource integration", Marketing Theory, Vol 12 No 2, pp.201-205.

Klingberg, T. (2009). The overflowing brain: Information overload and the limits of working memory. New York: Oxford University Press.

Komulainen, H. (2014). The role of learning in value co-creation in new technological B2B services. Journal of Business \& Industrial Marketing, Vol. 29 No. 3, 238-252.

Kozlenkova, I. V., Samaha, S. A., and Palmatier, R. W. (2014), "Resource-based theory in marketing”, Journal of the Academy of Marketing Science, Vol. 42 No 1, pp.1-21.

Ladley, D., Wilkinson, I., and Young, L. (2015), “The impact of individual versus group rewards on work group performance and cooperation: A computational social science approach", Journal of Business Research, Vol. 68 No.11, pp.2412-2425. 
Lafferty, B.A. and Tomas M. Hult, G. (2001, “A synthesis of contemporary market orientation perspectives", European Journal of Marketing, Vol. 35 No.1/2, pp.92-109.

Lambert, D. M. (2010), "Customer relationship management as a business process", Journal of Business and Industrial Marketing, Vol. 25 No. 1, pp.4-17.

Lenka, S., Parida, V., and Wincent, J. (2017). Digitalization capabilities as enablers of value co-creation in servitizing firms. Psychology \& Marketing, Vol. 34 No. 1, pp.92100.

Lin, Y., Wang, Y., \& Kung, L. (2015). "Influences of cross-functional collaboration and knowledge creation on technology commercialization: Evidence from high-tech industries", Industrial Marketing Management, 49, 128-138.

Ma, J. and Todorovic, Z. (2011), "Making universities relevant: Market orientation as a dynamic capability within institutions of higher learning", Academy of Marketing Studies Journal, Vol. 15 No. 2, pp.1-15.

Malone, T. W. (2018). How Human-Computer 'Superminds' Are Redefining the Future of Work. MIT Sloan Management Review, Vol. 59 No.4, pp.34-41.

Maltz, E., Souder, W. E., and Kumar, A. (2001), "Influencing R\&D/marketing integration and the use of market information by R\&D managers: intended and unintended effects of managerial actions", Journal of Business Research, Vol. 52 No. 1, pp.69-82.

Menguc, B. and Auh, S. (2006), "Creating a firm-level dynamic capability through capitalizing on market orientation and innovativeness", Journal of the Academy of Marketing Science, Vol. 34 No. 1, pp.63-73.

Menon, A., Jaworski, B.J. and Kohli, A.K. (1997), "Product quality: impact of interdepartamental interactions", Journal of the Academy of Marketing Science, Vol. 25 No. 3, pp.187-200.

Mohsen, K. and Eng, T.Y. (2016), “The antecedents of cross-functional coordination and their implications for marketing adaptiveness", Journal of Business Research, Vol 69 No. 12, pp.5946-5955.

Möller, K. and Svahn, S. (2003), "Managing strategic nets: A capability perspective", Marketing Theory, Vol. 3 No. 1, pp.209-234.

Mora Cortez, R. and Johnston, W.J. (2017), "The future of B2B marketing theory: A historical and prospective analysis", Industrial Marketing Management, 66, pp.90-102. 
Mora Cortez, Roberto and Johnston, W. J. (2018) Cultivating organizational wisdom for value innovation. Journal of Business \& Industrial Marketing, https://doi.org/10.1108/JBIM-11-2017-0292

Morales Mediano, J. and Ruiz-Alba, J. L. (2018), "New perspective on customer orientation of service employees: a conceptual framework", The Service Industries Journal, available at: www.tandfonline.com/doi/full/10.1080/02642069.2018.1455830.

Nakata, C., and Im, S. (2010), "Spurring cross-functional integration for higher new product performance: A group effectiveness perspective", Journal of Product Innovation Management, Vol. 27 No. 4, pp.554-571.

Narver, J. C. and Slater, S. F. (1990), "The effect of a market orientation on business profitability", Journal of Marketing, Vol. 54 No. 4, pp.20-35.

Neuman, D. (2014), "Qualitative research in educational communications and technology: A brief introduction to principles and procedures", Journal of Computing in Higher Education, Vol. 26 No 1, 69-86.

Nguyen, N. P., Ngo, L. V., Bucic, T., and Phong, N. D. (2018) "Cross-functional knowledge sharing, coordination and firm performance: The role of cross-functional competition”, Industrial Marketing Management, Vol. 71, pp.123-134.

Payne, A. and Frow, P. (2005), "A strategic framework for customer relationship management. Journal of Marketing”, Vol. 69 No. 4, pp.167-176.

Pfeffer, J. and Salancik, G. R. (1978). The external control of organizations: A resource dependence perspective. New York: Harper \& Row.

Ramirez, R. (1999), "Value co-production: Intellectual origins and implications for practice and research", Strategic Management Journal, Vol. 20 No. 1, pp.49-65.

Reid, D.J. and Reid, F. J. M. (2005), “Online Focus Groups: An In-depth Comparison of Computer-Mediated and Conventional Focus Group Discussions", International Journal of Market Research, Vol. 47 No. 22, pp.131-62.

Rogers, D. L. (2016). The digital transformation playbook: rethink your business for the digital age. Columbia University Press.

Rouziès, D., Anderson, E., Kohli, A. K., Michaels, R. E., Weitz, B. A., and Zoltners, A. A. (2005), "Sales and marketing integration: a proposed framework", Journal of Personal Selling \& Sales Management, Vol. 25 No. 2, pp.113-122.

Slater, S. F. and Narver, J. C. (1995), "Market orientation and the learning organization”, Journal of Marketing, Vol 59 No 3, pp.63-74. 
Schmieder, C. (2014) Software comparison. Available at:

https://website.education.wisc.edu/qdatools/wp-content/uploads/2014/12/Software-

Comparison.pdf (Accessed: 16 February 2018).

Stewart, D. W. and Shamdasani, P. (2017), "Online focus groups", Journal of Advertising, Vol. 46 No. 1, pp.48-60.

Tajeddini, K., Altinay, L., and Ratten, V. (2017), "Service innovativeness and the structuring of organizations: The moderating roles of learning orientation and interfunctional coordination", International Journal of Hospitality Management, Vol. 65, pp.100-114.

Talanquer, V. (2014), "Using qualitative analysis software to facilitate qualitative data analysis", in Bunce, D.M. and Cole, R.S. (eds.) Tools of chemistry education research. Washington, DC: American Chemical Society, pp.84-95.

Teece, D. J., Pisano, G., and Shuen, A. (1997), "Dynamic capabilities and strategic management”, Strategic Management Journal, Vol. 18 No. 7, pp.509-533.

Teece, D. J. (2007), "Explicating dynamic capabilities: the nature and microfoundations of (sustainable) enterprise performance", Strategic Management Journal, Vol. 28 No. 13, pp.1319-1350.

Teece, D. J. (2012), "Dynamic capabilities: Routines versus entrepreneurial action", Journal of Management Studies, Vol. 49 No. 8, pp.1395-1401.

Teece, D. J. (2014), "he foundations of enterprise performance: Dynamic and ordinary capabilities in an (economic) theory of firms", Academy of Management Perspectives, Vol. 28 No 4, pp.328-352.

Teece, D. J., Pisano, G. and Shuen, A. (1997), "Dynamic capabilities and strategic management”, Strategic Management Journal, Vol. 18 No. 77, pp.509-533.

Teece, D. J. (2014), “The foundations of enterprise performance: Dynamic and ordinary capabilities in an (economic) theory of firms", The Academy of Management Perspectives, Vol. 28 No. 24, pp.328-352.

Tsai, K. H. and Hsu, T. T. (2014), “Cross-functional collaboration, competitive intensity, knowledge integration mechanisms, and new product performance: A mediated moderation model”, Industrial Marketing Management, Vol. 3, pp.293-303.

Ulaga, W. (2003), "Capturing value creation in business relationships: A customer Perspective”, Industrial Marketing Management, Vol. 32 No. 8, pp.677-693. 
Ulaga, W. and Reinartz, W. J. (2011), "Hybrid offerings: how manufacturing firms combine goods and services successfully", Journal of Marketing, Vol. 75 No. 6, pp.5-23. Vesalainen, J. and Hakala, H. (2014), "Strategic capability architecture: The role of network capability”, Industrial Marketing Management, Vol. 43 No. 6, pp.938-950.

vom Brocke, J., Zelt, S., and Schmiedel, T. (2016). On the role of context in business process management. International Journal of Information Management, 36(3), 486-495. Wall, S. and Lepsinger, R. (1994), “Cross-functional obstacles”, Training, Vol. 5 No.2, pp.125-126.

Wernerfelt, B. (1984), “A resource-based view of the firm”, Strategic Management Journal, Vol. 5 No.2, pp.171-180.

Winter, S. G. (2003), “Understanding dynamic capabilities”, Strategic Management Journal, Vol. 24 No.1o, pp.991-995.

Wooldridge, B.R. and Minsky, B.D. (2002), "The role of climate and socialization in developing interfunctional coordination", The Learning Organization, Vol. 9 No. 1, pp.29-38.

Yin, R.K. (2015). Qualitative research: from start to finish. New York: Guilford Publications. 


\section{APPENDIX 1}

Table 2 Firms characteristics with participants' details of in depth interviews

Firms' characteristics

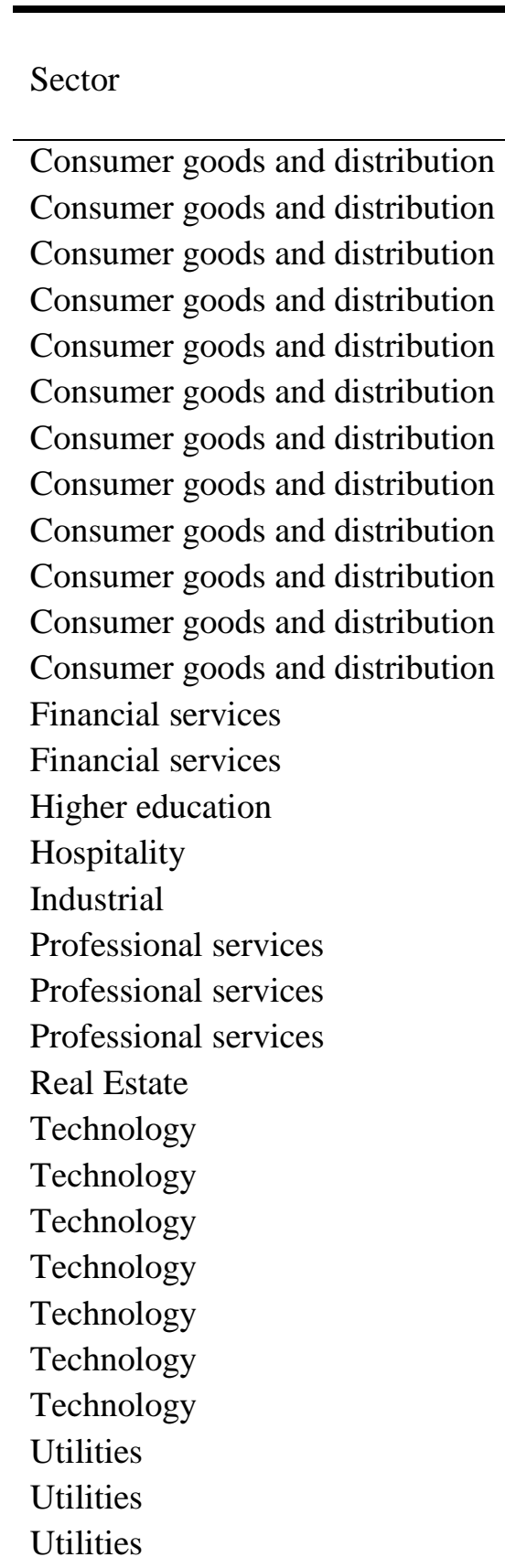

Participants' details

\section{Size}

Years of Years in the

Department

experience company

\section{Large enterprise}

Large enterprise

Large enterprise

SME

Large enterprise

Large enterprise

Large enterprise

Large enterprise

Large enterprise

Large enterprise

Large enterprise

Large enterprise

Large enterprise

Large enterprise

Large enterprise

Large enterprise

Large enterprise

SME

Large enterprise

SME

SME

SME

SME

SME

Large enterprise

Large enterprise

Large enterprise

Large enterprise

Large enterprise

Large enterprise

Large enterprise

\begin{tabular}{rrl}
$21-25$ & $16-20$ & General Management \\
$26-30$ & $11-15$ & General Management \\
$16-20$ & $<6$ & General Management \\
$21-25$ & $11-15$ & General Management \\
$21-25$ & $11-15$ & Marketing and sales \\
$16-20$ & $6-10$ & Marketing and sales \\
$11-15$ & $<6$ & Marketing and sales \\
$16-20$ & $16-20$ & Operations \\
$31-35$ & $6-10$ & HR \\
$26-30$ & $6-10$ & Strategy \\
$21-25$ & $6-10$ & Technology \\
$16-20$ & $6-10$ & Finance \\
$36-40$ & $>25$ & Quality \\
$16-20$ & $6-10$ & Strategy \\
$26-30$ & $>25$ & General Management \\
$21-25$ & $11-15$ & HR \\
$26-30$ & $21-25$ & Marketing and sales \\
$26-30$ & $16-20$ & Management \\
$16-20$ & $<6$ & Marketing and sales \\
$31-35$ & $<6$ & Sales \\
$16-20$ & $<6$ & Finance \\
$26-30$ & $16-20$ & General Management \\
$26-30$ & $6-10$ & General Management \\
$21-25$ & $6-10$ & Marketing and sales \\
$11-15$ & $<6$ & Technology \\
$16-20$ & $<6$ & General Management \\
$16-20$ & $6-10$ & General Management \\
$16-20$ & $6-10$ & General Management \\
$16-20$ & $6-10$ & Marketing and sales \\
$21-25$ & $16-20$ & Operations \\
$21-25$ & $<6$ & Technology \\
& & \\
\hline
\end{tabular}

